\title{
Whatever happened to the Golden Age of natural gas?
}

\author{
Tim Boersma ${ }^{1} \cdot$ Sarah M. Jordaan ${ }^{2}$
}

Received: 2 May 2017/ Accepted: 9 August 2017/Published online: 21 August 2017

(C) The Author(s) 2017. This article is an open access publication

\begin{abstract}
Recent technology innovation in the natural gas industry has powered a shale gas boom, enabling the narrative that natural gas is a transition fuel to a low-carbon future. However, this narrative has not manifested itself uniformly around the world and, more fundamentally, it must be tested and revised periodically to reflect rapidly changing market, supply chain, and environmental realities. The growth in production has put downward pressure on prices, incentivized increased consumption and trade in the coming years, leading to the coming of age of the global market for liquefied natural gas (LNG). LNG from areas with high levels of production can increasingly respond to demand growth elsewhere; however, questions about infrastructure availability, competition with other energy sources, and end use blur our understanding about environmental outcomes. New markets for natural gas face new medium and long-term challenges through capital investments in long-term infrastructure which creates a risk of displacing lower carbon options and prolonging higher emitting facilities. We explore the narrative of natural gas as a transition fuel, and how it has thus far manifested itself in various key markets. The United States is our region of focus on the supply side due to the recent shale gas boom and emission reductions from the coal-to-gas transition in the power sector. We make reference to producing regions involved in the international trade of liquefied natural gas. Questions related to demand from the European Union,
\end{abstract}

Tim Boersma

tb2720@sipa.columbia.edu

1 Center on Global Energy Policy, Columbia University, 1255 Amsterdam Avenue, New York, USA

2 Johns Hopkins SAIS, 1619 Massachusetts Avenue NW \#429, Washington, DC, USA
OECD Asia, and parts of non-OECD Asia are discussed. China and India-representing the centers of prolific anticipated demand growth-are discussed in terms of challenges to domestic supply growth and competing environmental and political objectives.

Keywords Natural gas · GHG emissions · Energy transition

\section{Natural gas as a transition fuel}

Prior to the shale boom in the United States, the position of natural gas as less GHG intense when compared to coal in the power sector was unquestioned. This changed with the shale boom, where new studies confirmed that the magnitude of methane leaks from natural gas production systems is uncertain and may even be great enough to change this broadly accepted assumption [1]. The most potent environmental argument in favor of natural gas in comparison to coal still holds: gas is a cleaner burning fossil fuel than coal and has substantially lower emissions of local air pollutants, such as $\mathrm{NO}_{x}$ and $\mathrm{SO}_{x}$. However, there are some important caveats complicating the argument that are specific to greenhouse gas emissions.

Life cycle assessments associated with natural gas production typically focus on power generation [2-6] and often assume that new natural gas-fired generation will displace coal-fired power plants [7-9]. To be sure, such displacement has enabled lower emissions in the US power sector [10]. The average emission intensity of natural gasfired power is approximately $60 \%$ lower than that of coalfired power $\left(430 \mathrm{~kg} \mathrm{CO}_{2} / \mathrm{MWh}\right.$ and $1000 \mathrm{~kg} \mathrm{CO} / \mathrm{MWh}$, respectively) [11]. To remain a climate benefit relative to coal in the power sector, research suggests that methane 
leaking from natural gas production systems-from well through delivery at a power plant-must be kept below $3.2 \%$ of natural gas produced [12]. Yet, the contribution of methane emissions from natural gas production systems to the life cycle remains uncertain [1, 12]. Measuring and regulating North American and European methane emissions appears to be manageable, though there is naturally some room for improvement. Technology to curtail methane emissions can be relatively cheap [13, 14], but the regulatory framework intended to ensure its application is being rolled back by the new Trump administration. Regulation is necessary not because the entire industry is reluctant to apply so-called green completion methods, but because the lack of regulation allows the worst performers to set the standard for the entire upstream industry-and potentially erode the social acceptance of unconventional oil and gas development in general.

Further to this challenge, the expansion of natural gas markets globally includes a burgeoning liquefied natural gas trade industry [7]. The life cycle emissions of the liquefied natural gas (LNG) value chain are also relatively poorly documented [15]. With the expansion of trade, the roles of the natural gas supply chain in exporting countries and of end use in importing countries become more prominent if we are to understand the impact of the industry on greenhouse gas emissions [8]. In exporting countries, emissions from natural gas production and infrastructure can contribute significantly to national and regional greenhouse gas emissions. For importing countries, the magnitude of emissions associated with the life cycle of natural gas depends on the end use and the efficiency of the end use processes associated with using the natural gas. Specific questions have been raised about the emission impacts and uncertainty around liquefaction plants [16], variability in power plants emissions [7], power plant efficiency [17], and natural gas end use [7, 8]. Given the recent and ongoing growth of the global LNG market, it is critical to improve our understanding of these factors and the overall climate implications of the expanding industry.

There is some empirical evidence that suggests that the long-term GHG emission reduction benefits of natural gas are negligible [18]. This argument is largely based on the notion that long-term investments in natural gas infrastructure crowd out investments in low-carbon technologies and energy efficiency [19].

The flexibility of gas-fired power plants relative to traditional large coal-fired plants was one of the primary reasons why natural gas was seen as a natural complement to intermittent renewables like solar and wind. Two developments are increasingly undermining this argument. First, renewables at a greater scale are becoming easier to manage with improving renewable systems' integration. The power sector has become better at forecasting weather patterns and the operation of wind farms and solar panels can now be highly optimized with big data analytics and machine learning, obviating the need for much of the balancing capacity. Exemplifying this improvement was the recent record set by the Southwest Power Pool achieving $52 \%$ wind energy on the grid on 1 day in February of 2017 [20]. This trend will likely be reinforced as various battery technologies become mature in the coming years, and electricity storage, even if not immediately at a large scale, can help balance the grid. It has been suggested that in some parts of the world significant fleets of electric vehicles might fulfill a similar role at some point. Second, new coal-fired electricity generation plants can be as flexible as gas turbines in balancing intermittent loads. And, of course, there is the promise of clean coal being a part of the future power grid, provided the release of pollutants-including greenhouse gas emissions-can be limited.

\section{The United States: shale unleashed}

The shale boom in the United States is one contributor to a global glut of natural gas that is unprecedented in recent decades. The growing industry influences the existing patchwork of international trade globally (Fig. 1). At the same time, the emergence of global liquefied natural gas trade is influencing the historically separate and regionalized market structure of the commodity. The LNG market is rapidly growing, particularly with large contributions from Australia the United States-the result is an anticipated over-supplied short-term market [21]. As part of this reconfiguration, the United States is poised to become a net exporter of natural gas perhaps as early as 2017 (Fig. 2).

The shale boom in the US has been notable, with a massive build-out of natural gas supplying primarily growth in the electricity sector and industry. The expansion of gas has mostly taken place at the expense of coal in the US energy mix. From 2010 to 2016, coal-fired electricity fell from 45 to $30 \%$ of utility-scale generation compared to natural gas-fired generation which increased from 24 to $34 \%$ [26]. In deregulated power markets, gas has also taken market share from nuclear energy in recent years [27]. Popular media has included reports on the remarkable reduction of energy-related $\mathrm{CO}_{2}$ emissions in the US being attributed exclusively to natural gas, but the reasons are somewhat more nuanced. Energy efficiency measures have also contributed to the emission decline, combined with the rapid growth in solar and wind power generation and a major economic recession. Still, the contribution of gas to US emission reduction efforts is most likely net positive in the short to medium term. In the United States the bridge fuel argument appears valid: the bridge has been built, the 


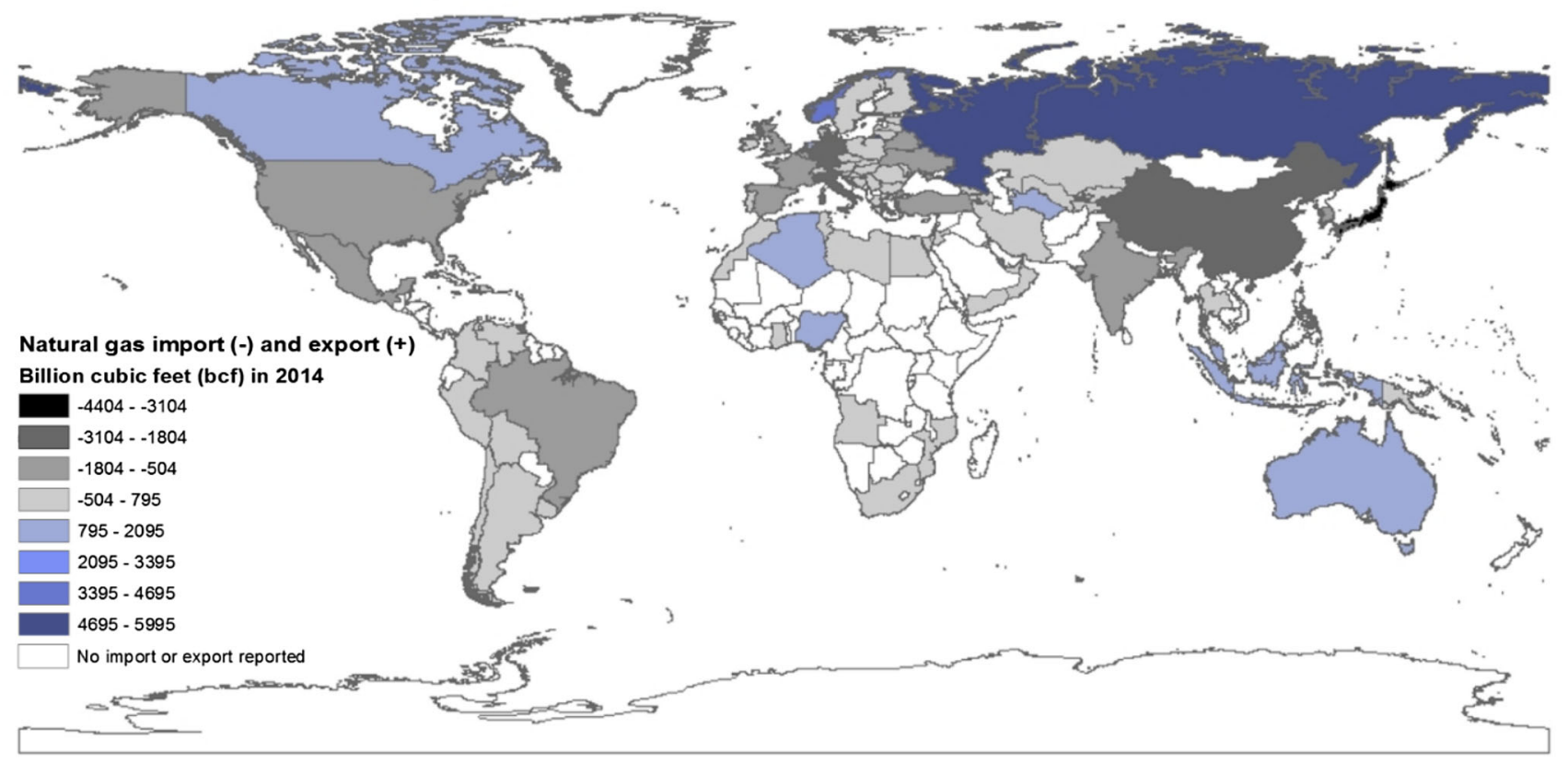

Fig. 1 Natural gas imports and exports by country in billion cubic feet, 2014 [22, 23]. Recent US data still fall within the range presented as the country continued to be a net importer of 0.7 trillion cubic feet (tcf) in 2016 [24]; however, trends indicate that the US will become a net exporter in the near future. Data extracted from the Energy Information Administration [22, 23] and mapped using ArcGIS. Country boundaries from World Countries shapefile, CESRI, DeLorme Publishing Company, Inc. 2016. All rights reserved
Fig. 2 Monthly natural gas imports to and exports from the United States in billion cubic feet (bcf) from 1997 to 2017, as reported by the Energy Information Administration [25]



only question is-to what? In other words, considering all investments in exploration, production, processing, distribution, and utilization, natural gas will likely play a very prominent role in the US energy economy in the coming decades, both domestically and internationally. The bridge fuel argument traditionally held that natural gas could function as a bridge to a low-carbon economy. The role natural gas will play on the other side of the bridge depends on a variety of factors such as markets, technology, price of alternatives, and policy, but is at this point by no means certain.

The previous administration took a careful look at medium- and long-term de-carbonization pathways, and attempted to reconcile the substantial build-out of natural gas with the long-term goal of deep de-carbonization. Most emission trajectories leading to a low-carbon energy system suggest that most natural gas-fired power plants will have to shut down or widely adopt carbon capture and sequestration (CCS) technologies by the mid-2030s, if we are to meet long-term de-carbonization targets [28]. Currently there is little reason to believe that CCS will be available as a commercially viable emission reduction tool as part of a wider mitigation portfolio, but this may change in the coming years [29].

In the short term, further curtailing methane emissions from the natural gas supply chain was a key objective of the previous administration. According to the US Environmental Protection Agency (EPA), the majority of 
methane emissions (about 66\%) from natural gas production systems occur during production and gathering, and technology to reduce those emissions is available at a relatively modest cost. ${ }^{1}$ Some companies already apply these technologies, others do not, and so the administration had proposed rules to require their application on federal and Indian lands. On private lands, where most natural gas production takes place, these rules would have to be installed at the state level. New rules in general are unlikely to be pursued under the current administration. Methane emissions are often associated with new shale gas production, but it is worth noting that old vertical wells have also been reported to have substantial leakage, for example in Colorado [30]. Methane emissions in midstream and downstream operations are more difficult to measure where the end uses are dispersed; for example, methane leaks from individual sources in urban centers may be challenging to detect. Several studies have examined leaks from urban systems [31]; however, ongoing measurements at the level of individual sources are challenging. Environmental Defend Fund has done a lot of work monitoring and measuring methane emissions, and has been among the leading advocates for methane emission reductions. Several studies in major urban areas, including in Boston and Washington, DC, found significant leakage rates, most likely because these urban areas have old distribution systems that are more prone to leakage [31]. Addressing these leaks is all the more challenging, because charging higher network rates to fix old distribution systems is often politically contentious.

Similar questions about methane emissions remain for other areas that contribute to supply or where supply growth is expected, namely China, Australia, Russia, the Caspian region, and some countries in Africa and the Middle East [21]. Under the last administration, America was active in methane measurement and regulation; however, some countries have been less inclined to develop similar programs. As a result, the US has led several initiatives to raise awareness, resulting in other countriesincluding Russia - to place higher emphasis on reducing methane emissions [32]. Challenges will remain in areas that are developing or where political priorities lie elsewhere. In the Middle East, for example, political priorities are diverse, ranging from attracting foreign direct investment (Iran), to stimulating natural gas usage in the power

\footnotetext{
${ }^{1}$ In the period between 1990 and 2015, methane emissions from natural gas and petroleum systems, measured together, decreased by $16 \%$. Most of this decline occurred in transmission $(-75 \%)$, distribution and storage $(-42 \%)$, and processing $(-48 \%)$, for instance by the increased use of plastic piping. A part of these gains was offset by an increase of $\mathrm{CH}_{4}$ emissions from production and gathering $(+51 \%)$. See EPA, 2017, p. 191. https://www.epa.gov/sites/produc tion/files/2017-02/documents/2017_complete_report.pdf.
}

sector at the expense of oil (KSA), dealing with questions related to increasing import dependence (e.g., Kuwait, Oman), or maintaining global market share (Qatar). In Africa, supply growth is now forecast to be on average $2.2 \%$ per year until 2021 , bolstered by the discovery of the mega-field Zohr in Egypt and major finds offshore Mozambique, Tanzania, Senegal, and Mauritania. The political priorities have been economic development; for example, through partnerships with international oil companies [21]. That said, the economic opportunities of mitigation have been demonstrated for some technologies [14], so the implementation of such innovations may improve the profitability of natural gas production in regions where natural gas development is continuing or growing.

Emissions are influenced by the end use for natural gas in addition to the infrastructure in the importing country, even more so in some cases when compared to upstream and midstream emissions. The diffusion of natural gas vehicles at the expense of conventional vehicles, for example, does not achieve the level of emission benefits that is expected from natural gas displacing coal-fired power [12]. For LNG export, it becomes increasingly complex to determine whether there will be a net benefit even if the natural gas is combusted for generating electricity. Many studies assume that natural gas-fired power is to displace coal [3]; however, nuclear, renewables, or even other sources of natural gas may be displaced [7, 8]. The ultimate source will depend on numerous factors, including the consuming country's power mix, the marginal source of new power domestically, market dynamics across energy choices, and the decision between available end uses.

Even though we currently have limited data to work with, we would be amiss if we would not touch on the ambitions of President Trump. Throughout his campaign, President Trump repeatedly promised to revive the coal industry, a promise that he has reiterated since he was sworn into office. There is increasing evidence that suggests new investments in coal-fired generation capacity will continue to be unlikely. Specifically, natural gas has become abundantly available enabling cost-competitiveness relative to coal power in recent years (assuming gas prices that continuously hover in the $\$ 2 / \mathrm{mmBtu}-\$ 3 /$ mmBtu range) [33] and the costs of renewable technologies (e.g., onshore wind and solar-PV) continues to decline [34] even reaching localized parity with fossil fuel options in regions where resources permit [35]. However, that does not inhibit this administration's ambition to support the coal industry's return: the roll-back of several pieces of legislation that encourage cleaner fuels and technologies may be successfully implemented. If fully implemented, the Trump agenda is anticipated to extend 
the lifetime of existing coal-fired generation capacity in various parts of the country by a number of years, at a minimum [36, 37].

\section{European Union: transition without natural gas?}

Various European countries are significant importers of Russian natural gas due to its large reserves, geographic location, and existing transmission infrastructure. Gazprom's dominance of the European gas market has fueled concerns over the geopolitics of natural gas in many European capital cities. The prominence of Russian natural gas is countered with proactive policies on reducing from the usage of fossil fuels, promoting alternative technologies, and integrating gas markets and enforcing the regulatory framework [38, 39]. Policy makers across Europe-particularly those in Brussels, and in Western and Southern European capitals_-like to pride themselves on a progressive stance when it comes to energy transition and carbon reduction. The European Union has long pursued ambitious policies to expand the share of renewable energy sources in the energy mix, improve energy efficiency, and reduce $\mathrm{CO}_{2}$ emissions with the implementation of a continent-wide system of emissions trading called Emissions Trading Scheme (ETS).

Following the historical narrative, one would expect natural gas to be a good fit for these European ambitions. To date, it has not been, for a variety of reasons. First, carbon pricing under the ETS has not resulted in carbon prices that make natural gas competitive with coal in the power sector. There are several structural reasons for this, most prominently an over-allocation of free emission allowances. This is slowly being addressed, but various member states are hesitant to be very ambitious, and several industries are resisting reforms as well. Second, natural gas has lost much of its appeal in the EU. Geopolitical concerns about dependence on Russian gas loom large, mostly in Central and Eastern Europe. Moreover, earth tremors following decade-long extraction of natural gas in the Netherlands have eroded public support for the resource in the continent's largest domestic producer [40]. This has led to the political decision to significantly scale down Dutch gas production, which in turn has increased import dependence [41]. Finally, the environmental community has successfully campaigned against shale gas exploration within the EU, despite the presence of potentially substantial shale gas resources in France and the United Kingdom, for example. To be sure, there are a number of reasons why commercial shale gas extraction may not occur in the EU, including various above-ground issues, such as cumbersome permitting procedures, as well as some below-ground challenges, such as difficult geological conditions [42].
The irony is that the EU has invested heavily in completing its internal market for natural gas, for example by supporting energy infrastructure projects of common interest under its Connecting Europe Facility [39]. Policy makers in Brussels would like to take more credit for what appears a successful European integration story, but are hindered because the resource has lost much of its appeal, and has become so controversial both amongst some Eastern European member states, for security reasons, and amongst the environmental community, which does not support the bridge fuel narrative. It remains to be seen whether natural gas will play a prominent role in Europe's electricity mix going forward. Perchance not all is doom and gloom for the natural gas industry in Europe. As a result of progressive air quality controls in, for instance, the transportation sector, subsectors like marine shipping may become attractive for natural gas in the form of LNG going forward. In addition, in Europe there is an ongoing debate about developing a hydrogen economy, and substantial research in power-to-gas technologies is underway. Finally, various countries support biogas development, even though it currently does not look like this will be a major contributor to Europe's gas mix in the near future.

\section{OECD Asia: price volatility? No, thank you}

Japan and South Korea have long been the world's largest importers of LNG. In both countries, policies to improve air quality in the 1960s were the primary drivers of increased natural gas consumption in subsequent years and decades. The resource was used both for peak load electricity generation and industrial processes. In the aftermath of the Fukushima nuclear disaster, Japan's entire nuclear fleet was shut down, the country's utilities and other major consumers scrambled to buy LNG on the spot market replace the idled nuclear capacity, and prices spiked [43].

South Korea did not experience the same shock, but it was similarly exposed to the same price volatility as Japan in the first half of this decade, nonetheless. Consequently, both countries have been hesitant to depend too heavily on natural gas as a resource, and both have embarked on alternative strategies as well. Japan, for example, implemented highly ambitious renewable and energy efficiency support programs [44]. Both Japan and South Korea have plans to substantially expand their respective coal-fired power-generating fleets to mitigate the risk of damaging fuel price volatility in the future [45]. Natural gas will continue to play a substantial role in the energy mix in OECD Asia, but a brief period of peak prices following the Fukushima disaster-combined with stagnant energy demand in Asia's mature economies-might have diminished the prospects of an outright natural gas renaissance in this part of the world. 
As importers, life cycle emissions associated with LNG in these counties depend on the end use of the commodity-in the case of electricity, the domestic power mix informs the emission implications. The uncertainty surrounding shocks thus has emission implications. Unpredictable exogenous events such as the disaster in Fukushima induce uncertainty in the type of power generation that may be displaced by new capacity fired by natural gas from LNG imports [8]. Specifically, new nuclear capacity may have been displaced if the disaster had not occurred; however, LNG imports competed with marginal oil-fired generation while Japan managed the large shutdown in power generation.

\section{Non-OECD Asia: keeping urban areas livable, but how to develop a market for gas?}

Perhaps unsurprisingly, natural gas has very significant potential in non-OECD Asia, with medium-term demand anticipated to grow by almost $3 \%$ per annum, from 303 billion cubic meters (bcm) in 2015 to 360 bcm in 2021 [21]. Environmental questions in non-OECD Asia go much farther than greenhouse gas emissions alone.

Air quality in major cities across Asia-particularly in China, India, and Pakistan — have been a major concern for residents and policy makers alike. Reportedly, Western diplomats with families are increasingly reluctant to relocate to these countries, as they are concerned for the health effects of poor air quality on their family members. Recent studies have suggested that poor air quality reduces life expectancy in Northeastern China by as much as 5.5 years [46]. Similar studies have started to emerge in India [47]. This is not sustainable. Natural gas is by no means a panacea, but it can play a role in cleaning up the air in major urban areas across developing Asia by displacing coal in electricity generation, diesel in transportation (in the form of compressed natural gas), and biomass in cooking and heating applications.

It is too early to tell what role natural gas will play in the energy transition pathways in non-OECD Asia. Gas demand is on course to grow substantially in most countries in the region, but this does not tell us much. More developed economies like China are actively pursuing policies to increase the share of natural gas in their primary energy mix. However, the outlook for natural gas in the region is clouded by the fact that natural gas markets in this part of the world remain mostly regulated, and-absent tighter emission regulations or a meaningful carbon price-gas will continue to face strong competition from oil products and coal. Markets are often dominated by state-owned companies, access to infrastructure is often not guaranteed, attracting foreign direct investments can be problematic, and fuel subsidies can cloud the investment outlook. In the case of China, policy makers have also actively supported the development of the local natural gas industry, because significant amounts of shale gas and coal bed methane are believed to be trapped under Chinese soil. As of 2015, China was producing a modest $0.01 \mathrm{bcm}$ per day ( $5 \mathrm{bcm}$ per year) of commercial shale gas, which is expected to grow steadily [48].

In less developed countries like India, the challenges are similar in terms of improving local air quality, but the government has other key challenges to consider as well, such as connecting hundreds of millions of people to the gas and electricity grid. With the exception of coal, India has the additional challenge of limited domestic resources (and surely limited domestic exploration) which brings questions about growing import bills and political concerns about import dependence [49]. Providing access to affordable energy comes ahead of environmental concerns and any fuel choice considerations in developing countries like India. In large parts of the country, the development of natural gas markets will take time: price distortions presently exist under the fully regulated market [50], infrastructure like grids and storage facilities will need to be built, and better connections between import facilities with major demand centers will need to be developed. The government has managed to stem the fall in domestic natural gas production, but it is uncertain whether commercial shale gas production in India should be anticipated any time soon, given aforementioned challenges.

\section{Conclusion}

A tentative conclusion is that as we progress towards lowcarbon economies there are opportunities to replace highcarbon resources in various economic activities with natural gas and improve local air quality. Such benefits are apparent with the substitution of coal-fired power generation, or oil products in electricity generation, in shipping, and other parts of the transportation sector. Yet, wherever this is done it is worth keeping in mind that natural gas is no panacea, and there is little evidence to support the idea that the fuel can play a role in a low-carbon economy, absent dramatic breakthroughs in technology that are currently not on the horizon. Expanding global natural gas markets create new doubts for not just the supply chain but also the end use of natural gas production. Greenhouse gas emissions occur across the supply chain of natural gasincluding both importing and exporting countries - and the variability across countries is still relatively unknown. Uncertainty in the future evolution of demand for natural gas, the end use of the commodity, and the displacement of existing fuels inhibits analysts from making definitive 
conclusions about the ultimate effect of natural gas on global greenhouse gas emissions. For countries and companies that have invested in natural gas as a bridge fuel, it is important to step up efforts to develop technologies that can help mitigate some of its negative externalities, or come up with alternative medium- to long-term scenarios. End use technologies such as power plants may have expected lifetimes of 40 years or more, shaping new questions about whether natural gas is a bridge fuel to a low-carbon economy or whether it may lead to sunk investment in high-carbon capital. While we focus specifically on the US supply due to the recent boom, questions about environmental outcomes and the abundant supply internationally are relevant for other producing countries involved with the international trade of natural gas. With the success of the coal-to-gas substitution in reducing emissions from the US power sector and an increasingly globalized market, decision-makers across the public and private sector should not overlook their necessary participation in ensuring long-term emission benefits from a growing natural gas sector.

Open Access This article is distributed under the terms of the Creative Commons Attribution 4.0 International License (http://creative commons.org/licenses/by/4.0/), which permits unrestricted use, distribution, and reproduction in any medium, provided you give appropriate credit to the original author(s) and the source, provide a link to the Creative Commons license, and indicate if changes were made.

\section{References}

1. Brandt, A.R., Heath, G.A., Kort, E.A., O'Sullivan, F., Ptron, G., Jordaan, S.M., Tans, P., Wilcox, J., Gopstein, A.M., Arent, D.: Methane leaks from North American natural gas systems. Science 343, 733-735 (2014)

2. Heath, G.A., O'Donoughue, P., Arent, D.J., Bazilian, M.: Harmonization of initial estimates of shale gas life cycle greenhouse gas emissions for electric power generation. Proc. Natl. Acad. Sci. 111, E3176 (2014)

3. Skone, T.J., James, R., Cooney, G., Ivey, K., Jamieson, M., Littlefield, J., Marriott, J.: Life cycle analysis: Natural Gas Combined Cycle (NGCC) Power Plant. DOE/NETL-403-110509 (2012)

4. Weber, C.L., Clavin, C.: Life cycle carbon footprint of shale gas: review of evidence and implications. Environ. Sci. Technol. 46, 5688-5695 (2012)

5. Jiang, M., Griffin, W.M., Hendrickson, C., Jaramillo, P., VanBriesen, J., Venkatesh, A.: Life cycle greenhouse gas emissions of Marcellus shale gas. Environ. Res. Lett. 6, 034014 (2011)

6. Venkatesh, A., Jaramillo, P., Griffin, W.M., Matthews, H.S.: Uncertainty in life cycle greenhouse gas emissions from United States natural gas end-uses and its effects on policy. Environ. Sci. Technol. 45, 8182-8189 (2011)

7. Coleman, J. W., Kasumu, A. S., Liendo, J., Li, V., Jordaan, S. M.: Calibrating Liquefied Natural Gas Export Life Cycle Assessment: Accounting for Legal Boundaries and Post-Export Markets. CIRL Occasional Paper \#49. Canadian Institute of Resources Law (2015)
8. Coleman, J.W., Jordaan, S.M.: Clearing the Air: How Canadian LNG Exports Could Help Meet World Greenhouse Gas Reduction Goals. C. D. Howe Institute, Toronto (2016). (issue brief)

9. Skone, T., Engineer, P. S. E.: Role of alternative energy sources: natural gas technology assessment. NETL Office of Strategic Energy Analysis and Planning (2012)

10. Larsen, K., Delgado, M., Marsters, P.: Untapped Potential: Reducing Global Methane Emissions from Oil and Natural Gas Systems. Rhodium Group LLC, New York (2015)

11. Office of Energy Policy and Systems Analysis.: U.S. Department of Energy. Environment Baseline, Volume 1: Greenhouse Gas Emissions from the U.S. Power Sector (2016)

12. Alvarez, R.A., Pacala, S.W., Winebrake, J.J., Chameides, W.L., Hamburg, S.P.: Greater focus needed on methane leakage from natural gas infrastructure. Proc. Natl. Acad. Sci. U S A. 109, 6435-6440 (2012)

13. ICF International.: Economic Analysis of Methane Emission Reduction Opportunities in the U.S. Onshore Oil and Natural Gas Industries. Prepared for the Environmental Defense Fund (2014)

14. Warner, E., Steinberg, D., Hodson, E., Heath, G.: Potential CostEffective Opportunities for Methane Emission Abatement. Joint Institute for Strategic Energy Analysis, NREL/TP-6A50-63828 (2015)

15. Stephenson, E., Doukas, A., Shaw, K.: Greenwashing gas: might a 'transition fuel'label legitimize carbon-intensive natural gas development? Energy Policy 46, 452-459 (2012)

16. Abrahams, L.S., Samaras, C., Griffin, W.M., Matthews, H.S.: Life cycle greenhouse gas emissions from US liquefied natural gas exports: implications for end uses. Environ. Sci. Technol. 49, 3237-3245 (2015)

17. Skone, T., Littlefield, J., Marriott, J., Cooney, G., Jamieson, M., Hakian, J., Schivley, G.: Life Cycle Analysis of Natural Gas Extraction and Power Generation. US Department of Energy, National Energy Technology Laboratory, Morgantown (2014)

18. Davis, S.J., Shearer, C.: Climate change: a crack in the naturalgas bridge. Nature 514, 436-437 (2014)

19. McJeon, H., Edmonds, J., Bauer, N., Clarke, L., Fisher, B., Flannery, B.P., Hilaire, J., Krey, V., Marangoni, G., Mi, R.: Limited impact on decadal-scale climate change from increased use of natural gas. Nature 514, 482-485 (2014)

20. Southwest Power Pool.: SPP sets North American record for wind power. https://www.spp.org/about-us/newsroom/spp-sets-northamerican-record-for-wind-power/. Accessed 25 March 2017

21. International Energy Agency.: Medium Term Gas Market Report: Market Analysis and Forecast to 2021 (2016)

22. Energy Information Administration (EIA).: International Energy Statistics. Exports of Dry Natural Gas 2014. https://www.eia.gov/ beta/international/data/browser/\#/?pa=000000000000000001\&c= ruvvvvvfutvnvv1 1 ruvvvfvvvvvvvfvvvou20evvvvvvvvvnnvvu vo\&ct $=0 \& \mathrm{tl} \_\mathrm{id}=3002-\mathrm{A} \& \mathrm{vs}=\mathrm{INTL} .26-4-\mathrm{AFG}-\mathrm{BCF} . \mathrm{A} \& \mathrm{vo}=$ $0 \& v=H \& s t a r t=1990 \&$ end $=2014$. Accessed 27 April 2017

23. Energy Information Administration (EIA).: International Energy Statistics. Imports of Dry Natural Gas 2014. https://www.eia.gov/ beta/international/data/browser/\#/?pa=0000000000001\&c= ruvvvvvfvtvnvv1 urvvvvfvvvvvvfvvvou20evvvvvvvvvnvvu vo\&ct=0\&tl_id=3002-A\&vs=INTL.26-3-AFG-BCF.A\&vo= $0 \& v=H \&$ start $=1990 \&$ end $=2014$. Accessed 27 April 2017

24. Energy Information Administration (EIA).: Natural Gas Explained: Natural Gas Imports and Exports. https://www.eia. gov/energyexplained/index.cfm?page=natural_gas_imports. Accessed 01 May 2017

25. Energy Information Administration (EIA).: Natural Gas, Imports/ Exports. https://www.eia.gov/naturalgas/data.cfm\#imports. Accessed 02 May 2017 
26. Energy Information Administration (EIA).: Electricity data. https://www.eia.gov/electricity/data.php\#generation. Accessed 26 May 2017

27. Energy Information Administration (EIA).: US energy-related carbon dioxide emissions in 2015 are $12 \%$ below their 2005 levels. https://www.eia.gov/todayinenergy/detail.php?id=26152. Accessed 24 March 2017

28. Benoit, P.: From Paris to Marrakesh and beyond: Where do we want to go and how can we get there. https://csis-prod.s3.ama zonaws.com/s3fs-public/event/170131_Benoit_Presentation. pdf?q0JbW2hEwaeuxUEUr1QV5yV27m8ad..W. Accessed 24 March 2017

29. Banks, J., Boersma, T.: Fostering Low Carbon Energy Next Generation Policy to Commercialize: CCS in the United States. Brookings Energy Security and Climate Initiative (2015)

30. Sherwood, O.A., Rogers, J.D., Lackey, G., Burke, T.L., Osborn, S.G., Ryan, J.N.: Groundwater methane in relation to oil and gas development and shallow coal seams in the Denver-Julesburg Basin of Colorado. Proc. Natl. Acad. Sci. U S A. 113, 8391-8396 (2016)

31. McKain, K., Down, A., Raciti, S.M., Budney, J., Hutyra, L.R., Floerchinger, C., Herndon, S.C., Nehrkorn, T., Zahniser, M.S., Jackson, R.B., Phillips, N., Wofsy, S.C.: Methane emissions from natural gas infrastructure and use in the urban region of Boston, Massachusetts. Proc. Natl. Acad. Sci. U S A. 112, 1941-1946 (2015)

32. Pacific Northwest National Laboratory.: Methane Mitigation Seminar for Russia's Oil and Gas Production. http://www.pnnl. gov/science/highlights/highlight.asp?id=1141. Accessed 25 March 2017

33. Energy Information Administration (EIA).: Levelized Cost and Levelized Avoided Cost of New Generation Resources in the Annual Energy Outlook 2015. https://www.eia.gov/outlooks/ archive/aeo15/pdf/electricity_generation_2015.pdf. Accessed 26 May 2017

34. Taylor, M., Ralon, P., Ilas, A.: The Power to Change: Solar and Wind Cost Reduction Potential to 2025. IRENA (2016). http:// www.irena.org/DocumentDownloads/Publications/IRENA_Power_ to_Change_2016.pdf. Accessed 10 May 2017

35. Bloomberg New Energy Finance: Sustainable Energy in America: Factbook 2016. Business Council for Sustainable Energy, Washington (2014)

36. Energy Information Administration (EIA).: Analysis of the impacts of the clean power plan. https://www.eia.gov/analysis/ requests/powerplants/cleanplan/pdf/powerplant.pdf. Accessed 30 May 2017

37. Houser, T., Bordoff, J., Marsters, P.: Can coal make a comeback? Center on Global Energy Policy, Columbia University, New York (2017)

38. Goldthau, A., Sitter, N.: A Liberal Actor in a Realist World: The European Union Regulatory State and the Global Political Economy of Energy. OUP, Oxford (2015)

39. Boersma, T.: Energy Security and Natural Gas Markets in Europe: Lessons from the EU and the United States. Routledge, Abingdon (2015)

40. Boersma, T.: The end of Dutch natural gas production as we know it. https://www.brookings.edu/blog/order-from-chaos/2016/ 08/04/the-end-of-dutch-natural-gas-production-as-we-know-it/. Accessed 24 March 2017

41. Mitrova, T., Boersma, T., Galkina, A.: Some future scenarios of Russian natural gas in Europe. Energy Strat. Rev. 11, 19-28 (2016)

42. Johnson, C., Boersma, T.: Energy (in) security in Poland the case of shale gas. Energy Policy 53, 389-399 (2013)

43. Boersma, T., Losz, U.: Forthcoming

44. Fairley, P.: Can Japan Recapture Its Solar Power? https://www. technologyreview.com/s/533451/can-japan-recapture-its-solarpower/. Accessed 24 March 2017

45. Richardson, N.: Japan plans to build 45 new coal power plants in next decade: EIA. http://www.platts.com/latest-news/coal/syd ney/japan-plans-to-build-45-new-coal-power-plants-27762428. Accessed 24 March 2017

46. Chen, Y., Ebenstein, A., Greenstone, M., Li, H.: Evidence on the impact of sustained exposure to air pollution on life expectancy from China's Huai River policy. Proc. Natl. Acad. Sci. U S A. 110, 12936-12941 (2013)

47. Ghude, S.D., Chate, D., Jena, C., Beig, G., Kumar, R., Barth, M., Pfister, G., Fadnavis, S., Pithani, P.: Premature mortality in India due to PM2. 5 and ozone exposure. Geophys. Res. Lett. 43, 4650-4658 (2016)

48. Energy Information Administration (EIA):: Shale gas production drives world natural gas production growth. https://www.eia.gov/ todayinenergy/detail.php?id=27512. Accessed 30 May 2017

49. Ahn, S., Graczyk, D.: Understanding Energy Challenges in India: Policies, Players, and Issues, p. 24. IEA, Paris (2012)

50. Boersma, T., Losz, A., Ummat, A.: The Future of Natural Gas in India: A Country at a Crossroads. Center on Global Energy Policy, Columbia University, New York (2017) 